\title{
Dual Insurances Design Achieves Long-Life Cycling Li-metal Batteries under Wide Temperature Range
}

\author{
Wei Fan ${ }^{a, b, c^{\perp}}$, Xiuling Zhang ${ }^{a, b, c}{ }^{\perp}$ Congju Lia $a^{*}$ \\ ${ }^{a}$ School of Energy and Environmental Engineering, University of Science and Technology \\ Beijing, Beijing 100083, China. Beijing Key Laboratory of Resource-oriented Treatment of \\ Industrial pollutants, Beijing 100083, China \\ ${ }^{\mathrm{b}}$ University of Chinese Academy of Sciences, Beijing 100049, P. R. China. \\ *Corresponding author: congjuli@126.com \\ $\perp$ These authors contribute equally to this work.
}

All the chemicals, containing Poly-vinylidene fluoride-hexafluoropropylene $(\mathrm{PVDF}-\mathrm{HFP}) \quad(\mathrm{Mn}=130000) \quad($ Aldrich $), \quad \mathrm{Al}_{2} \mathrm{O}_{3} \quad$ nanoparticles $\quad(200-300 \mathrm{~nm})$ (Damas-beta), Methl Methacrylate (MMA) (Aldrich), polycarbonate (PC) (Aldrich), 2,2-azobisisobutyronitrile (AIBN) (Damas-beta), N,N-dimethyl for mamide dimethyl acctel (DMF) (Aladdin) are used as received. The liquid electrolyte applied in this experiment is $1 \mathrm{M}$ LiTFSI in PC.

Material properties of CPE membrane: 


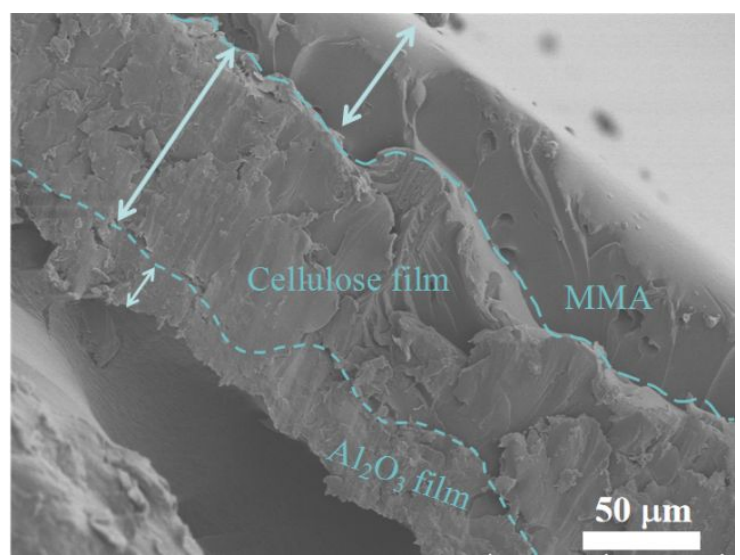

Figure S1. The thickness of different layer of CPE membrane.
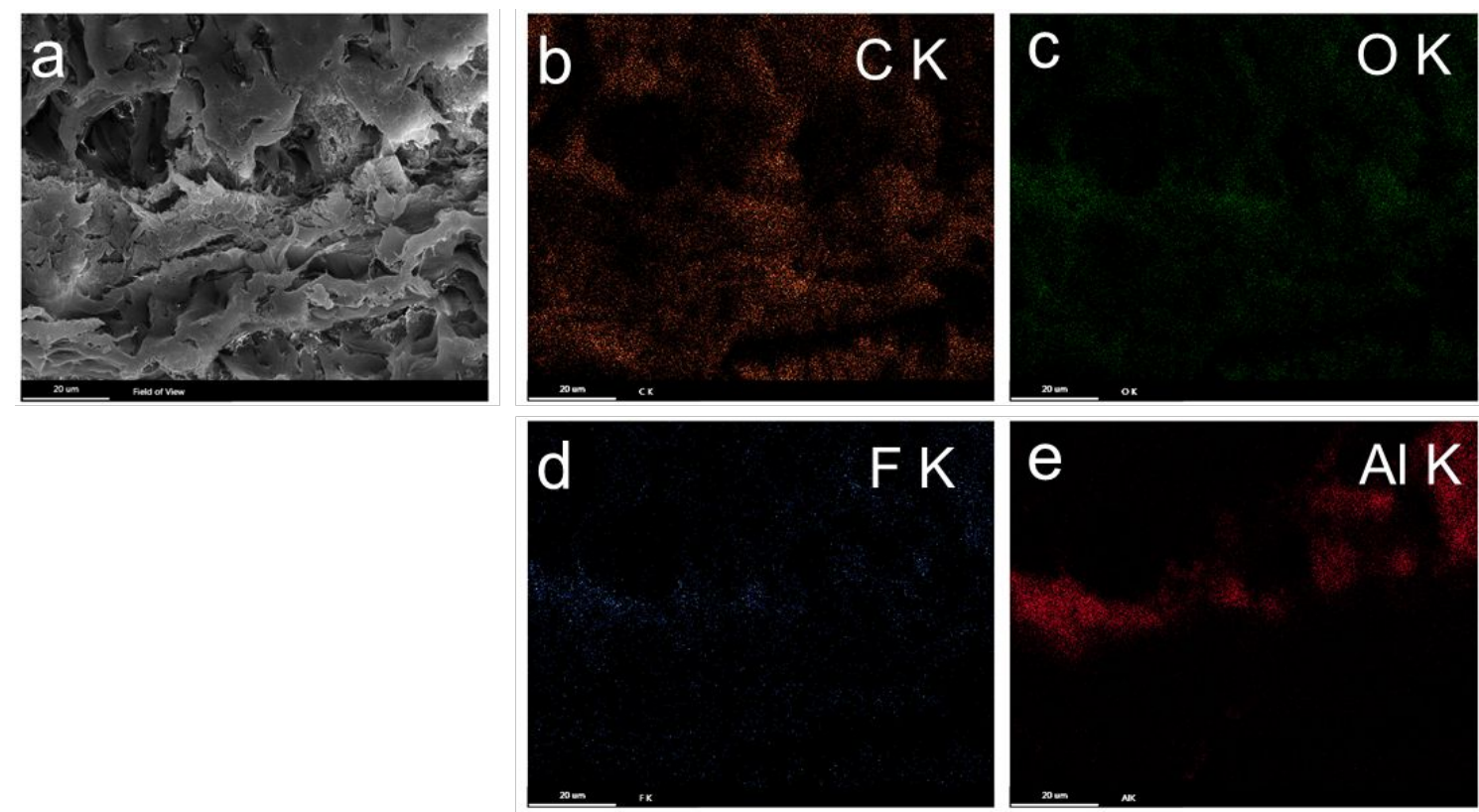

Figure S2. (a) SEM cross section of CPE membrane. Elements dispersion of (b) C; (c) $\mathrm{O}$; (d) F; (e) Al. 


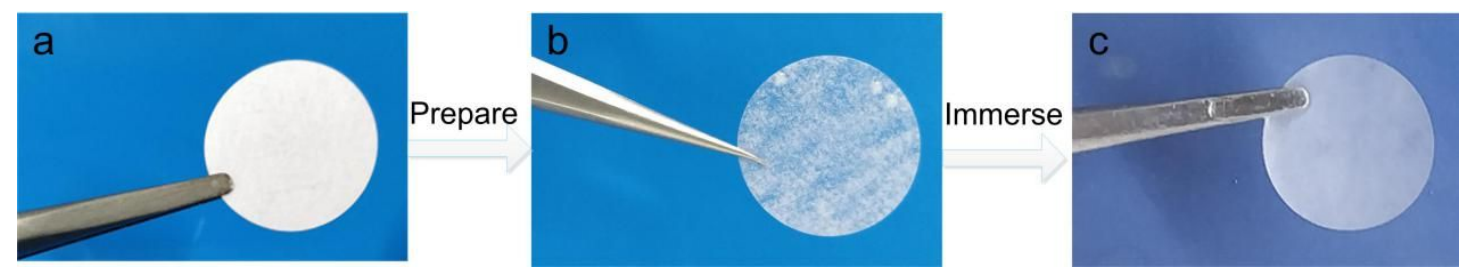

Figure S3. Photographs of (a) the original cellulose membrane; (b) after being electrospun $\mathrm{Al}_{2} \mathrm{O}_{3}$ layer and coated by in-situ MMA polymerization; (c) after being immersed into the LiTFSI/PC liquid electrolyte.
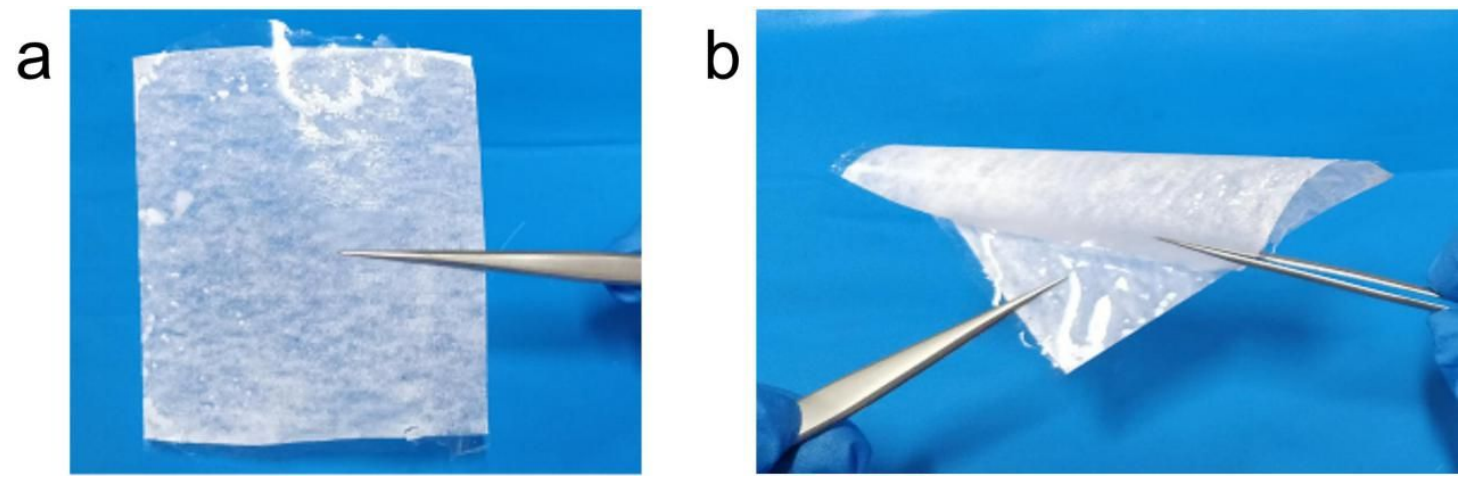

Figure S4. Photographs of (a) the large-scale of prepared membrane; (b) the flexibility of the prepared membrane.] 
Electrochemical properties of CPE:

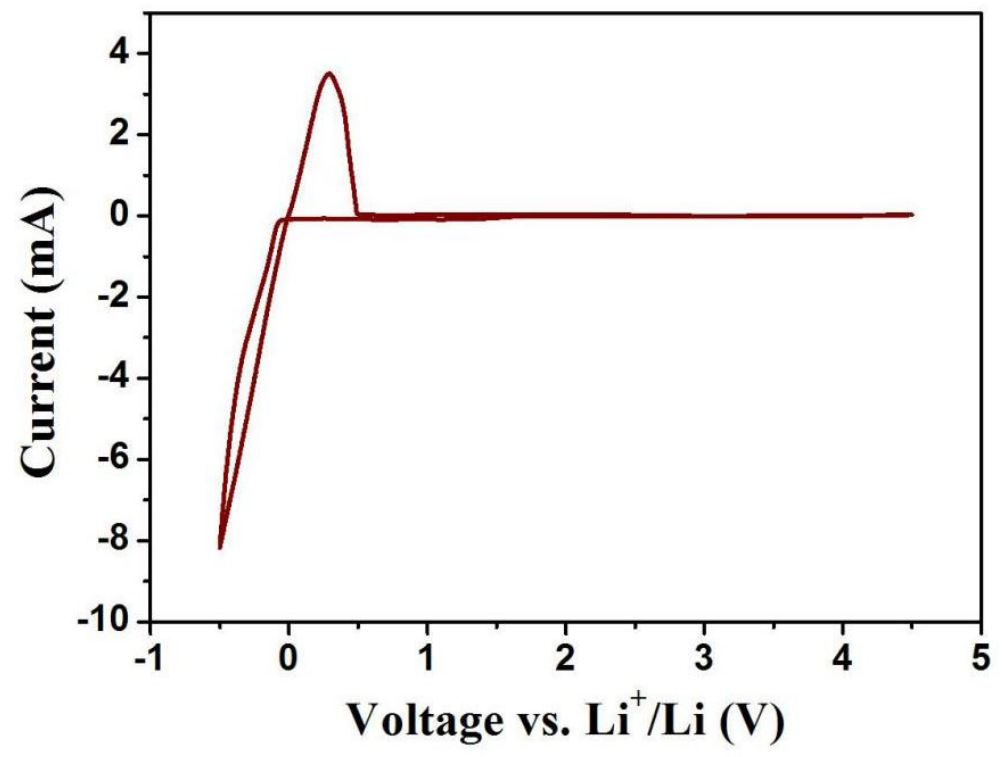

Figure S5. CV of the Li|CPE|SS.

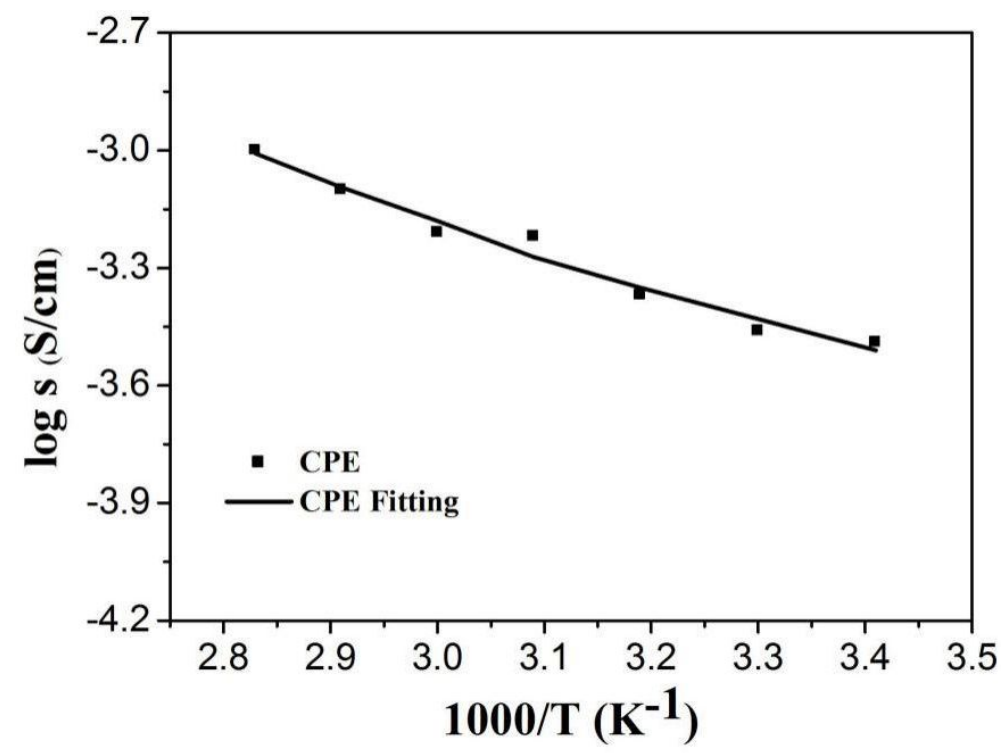

Figure S6. Ionic conductivity change with the elevation of temperature. 


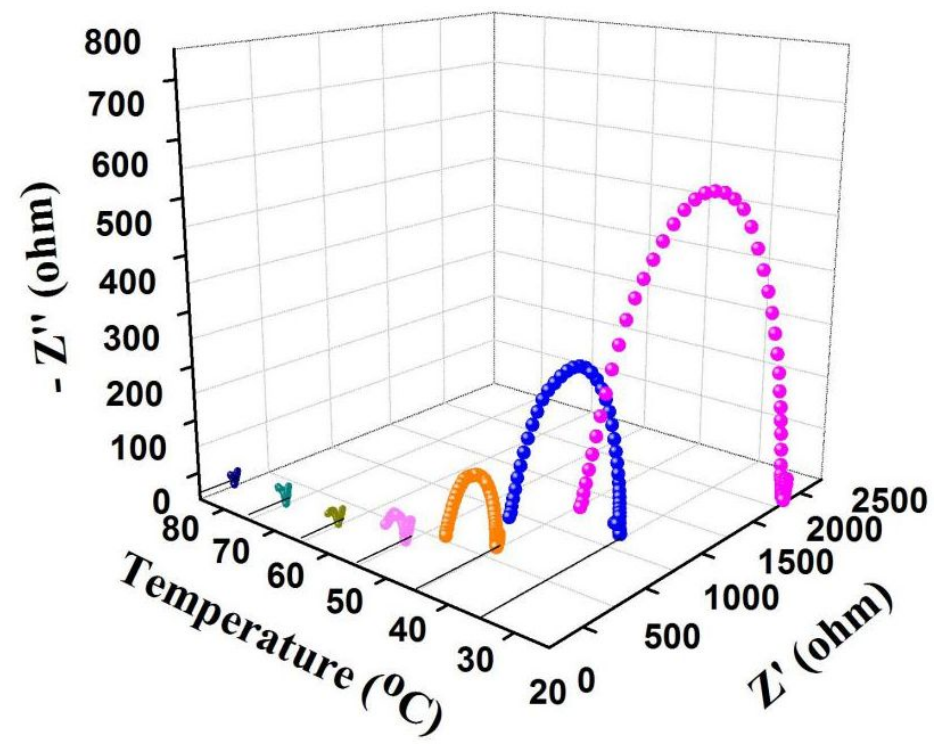

Figure S7. Impedance change with temperature of $\mathrm{Li}|\mathrm{CPE}| \mathrm{Li}$ cell.

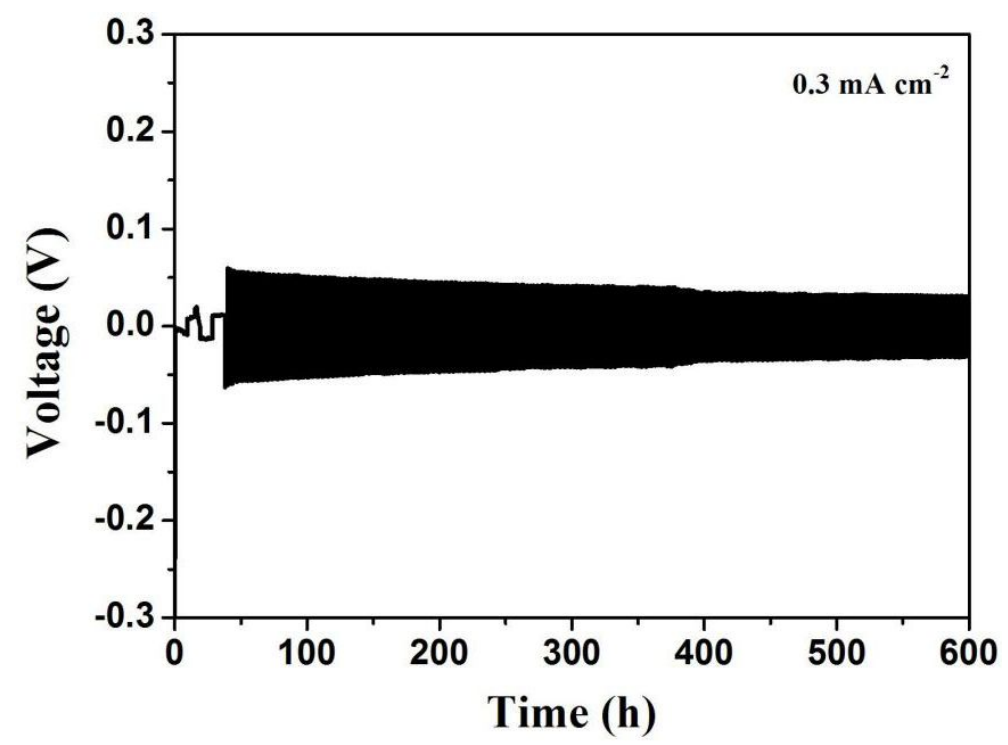

Figure S8. Li|CPE $\mid$ Li stripping and plating process under $0.3 \mathrm{~mA} \mathrm{~cm}{ }^{-2} 1 \mathrm{mAh} \mathrm{cm}^{-2}$. 

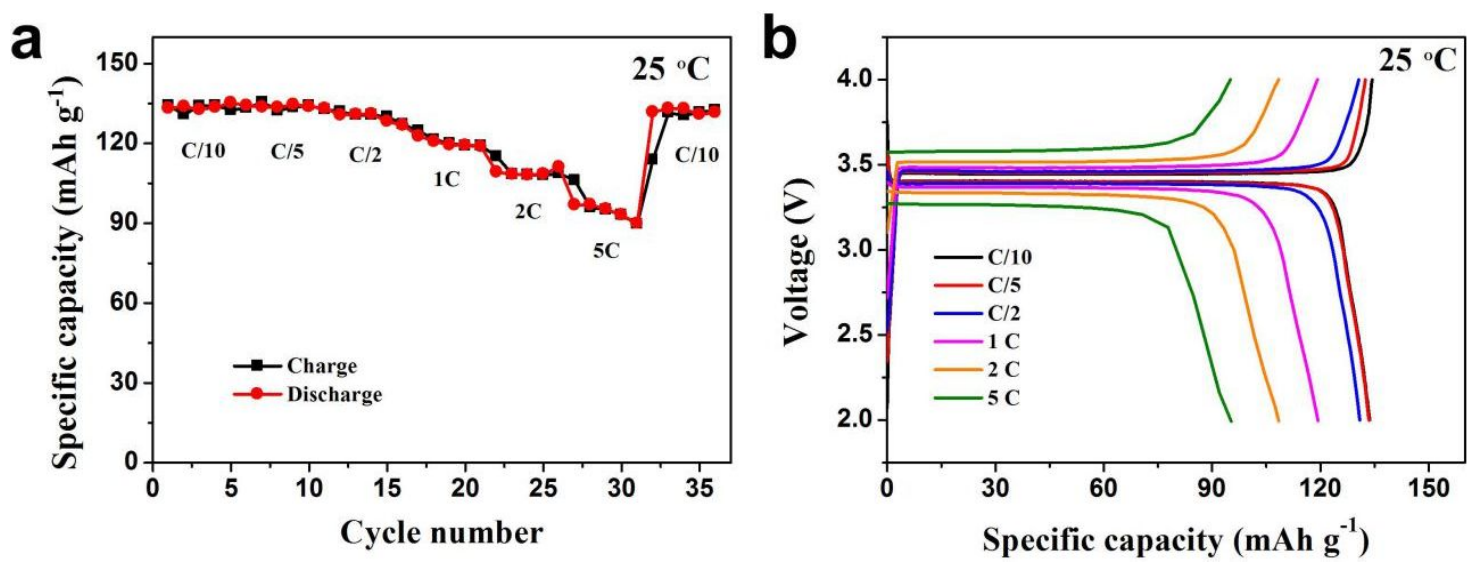

Figure S9. (a) The ratability test of CPE-based $\mathrm{LMB}$ at $25^{\circ} \mathrm{C}$ from $0.1 \mathrm{C}$ to $5 \mathrm{C}$; (b)

The charge/discharge profiles of CPE-based LMB at $25^{\circ} \mathrm{C}$ from $0.1 \mathrm{C}$ to $5 \mathrm{C}$.

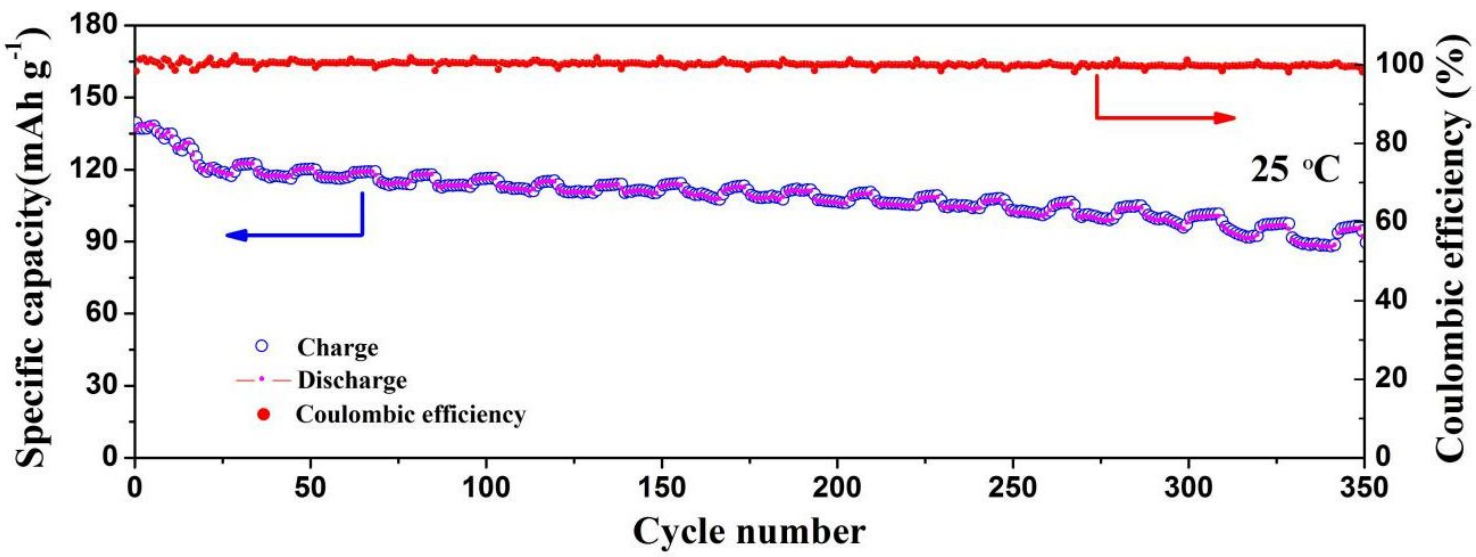

Figure S10. The cycle performance of CPE-based LMB under $25{ }^{\circ} \mathrm{C}$ under $0.5 \mathrm{C}$. 


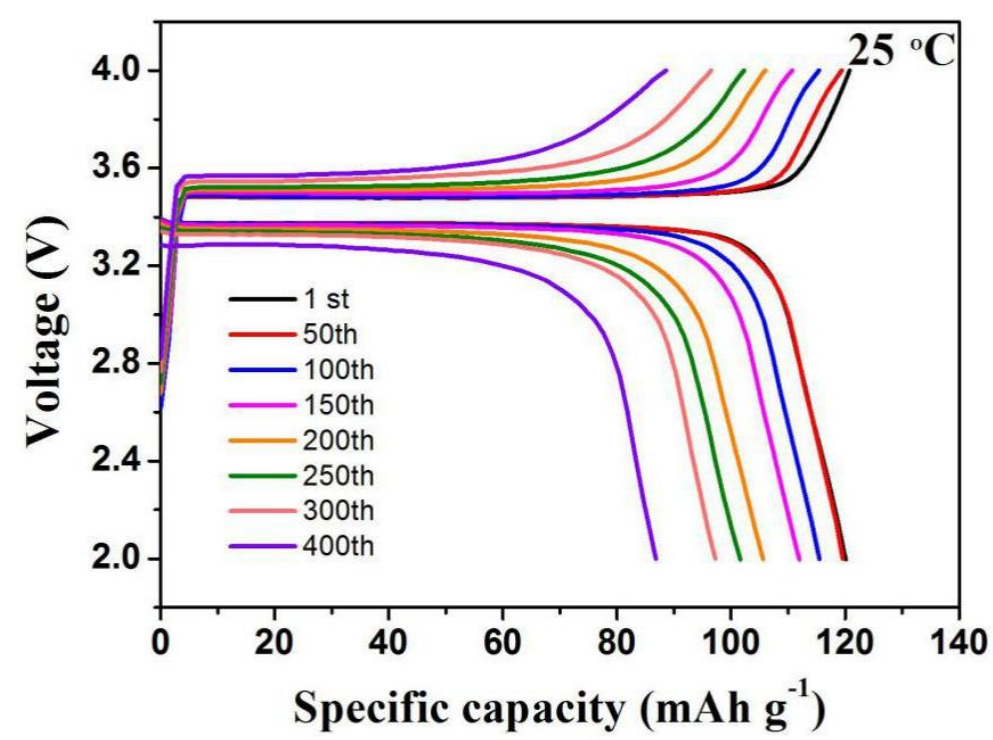

Figure S11. The typical charge/discharge profiles of CPE-based LMB at $25^{\circ} \mathrm{C}$.

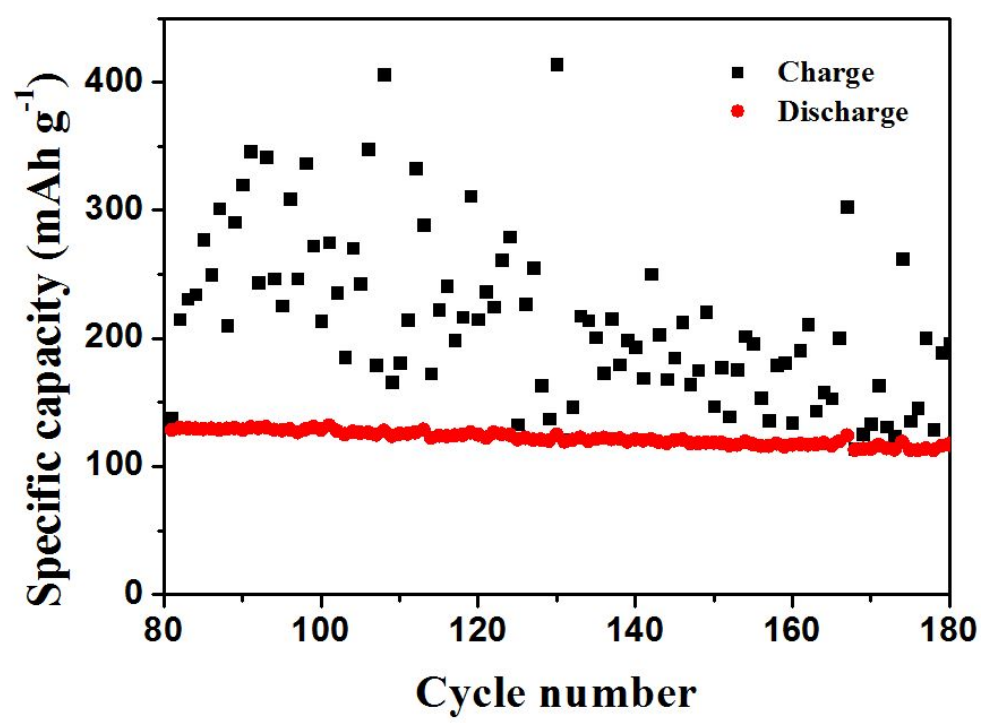

Figure S12. The cycling performance of LFP|LiTFSI liquid electrolyte|Li at $1 \mathrm{C}$ under $50^{\circ} \mathrm{C}$. 